American Journal of Applied Sciences 9 (10): 1678-1683, 2012

ISSN 1546-9239

(C) 2012 Science Publication

\title{
Compare the Effects of two Educational Methods on the Health Principles Knowledge of Employees in Food Preparation
}

\author{
${ }^{1}$ Fereshteh Farzianpour, \\ ${ }^{2}$ Gholamreza Jahed Khaniki, ${ }^{3}$ Farjad Batebi and ${ }^{2}$ Masood Yunesian \\ ${ }^{1}$ Department of Health Management and Economic, \\ ${ }^{2}$ Department of Environmental Health Engineering, \\ School of Public Health, Tehran University of Medical Sciences, Tehran, Iran \\ ${ }^{3}$ Department of Environmental Health, \\ Health School, Semnan University of Medical Sciences, Semnan, Iran
}

\begin{abstract}
Problem statement: Conducting educational programs to enhance the knowledge of food preparation and distribution commerce is important in achieving health and food safety. This study aimed to compare the effects of two educational methods (book let and trade school) on the health principles knowledge of employees in food preparation and supply centers. Approach: In this crosssectional study, 420 employees who were working at food supply centers in Semnan were entered. They were divided into three groups. Two groups received educational programs regarding health principles and food safety practice; one group was trained at a trade school (135 cases) and one group using booklet as a distant learning method (145 cases). 140 employees received no educational intervention and were considered as the control group. Knowledge of these groups in terms of health principles and food safety practice was assessed and compared before and after educational intervention. Results: Analysis of Variance (ANOVA) results after the educational intervention showed a significant difference between each of the two educated groups (either by trade school or booklet) in comparison to the control group $(\mathrm{p}<0.001)$. No significant difference was seen between the two educated groups $(\mathrm{p}=0.593)$. Difference in the rate of the knowledge of each of the trained groups before and after intervention was significant, with minimal difference. Conclusion: It was concluded that the important thing according to observed findings is comparison of mean scores in both educated groups after intervention did not show considerable increase. There is a requirement to develop training methods that they could change knowledge as well as behavior.
\end{abstract}

Key words: Effect, educational methods, food preparation, educational intervention, educational methods, food safety practice, Analysis of Variance (ANOVA)

\section{INTRODUCTION}

With increasing population, preparation of enough food is one of the complicated and critical issues in different countries, especially in developing ones. Besides lack of sufficient food, problems in these countries include non-compliance with health standards throughout preparation, conversion, storage, distribution and food consumption. Food stuff is considered as one of the most important sources of food contamination by chemical and biological agents. It is estimated that $70 \%$ of infectious diseases are transmitted to humans through unhealthy food and more than 450 types of viral, parasitic, fungal and microbial diseases can be transmitted to humans through foods with animal origin (Pilling et al., 2008). Food hygiene training can be a main necessity in food industry and should place as a part of an effective food safety management strategy. Education and training will lead to an improvement in food safety if the knowledge imparted leads to suitable changes in behavior at the workplace (Kassa et al., 2010). The development of evaluation criteria for the effectiveness of training is very important to protect public health (Marriott, 1999; Park et al., 2010; Gomes et al., 2011).

Corresponding Author: Fereshteh Farzianpour, Department of Health Management and Economics, School of Public Health, Tehran University of Medical Sciences, Tehran, Iran Tel: +98-2144648943 
Utilization of educational methods can be effective and successful for increasing the knowledge about food safety and preventing food borne illness throughout the world (Medeiros et al., 2001; Choudhury et al., 2011; Powell et al., 2011). Providing safe food is a necessary prerequisite for ensuring society health, which is one of the important indices of development. This objective is achieved only through increasing education and awareness of different social groups. Education is the key element in development of a society and it is one of the most important strategies to ensure successful health programs (Egan et al., 2007; Montenegro et al., 2008; Seaman, 2010).

Teaching food handlers can be the most important indices of development in food establishments. Effective education can improve the knowledge, attitude and skills. Some studies have done about effectiveness of instructional techniques for teaching food safety and hygiene principles in food employees of USA (Costello et al., 1997), Canada (Howes et al., 1996), UK (Kirby and Gardiner, 1997; Seaman, 2010) and Bahrain (Nabali et al., 1986). Most studies in food hygiene and safety education courses persist highly on the increasing of information and the evaluating the education method, education content and its design can be important in training. Personnel of food preparation and supply centers are one of the groups which affect food safety and health. Performance of educational programs in terms of food hygiene knowledge with the aim of increasing their knowledge is effective in reaching the goal of food safety and health. Educating of food handlers and administers can be influential in application of health principles in food preparation and supply centers for reducing food Safety and hygiene affairs. In this study, we investigated the knowledge level of food preparation, distribution and supply centers employees, with the objective of need assessment and educational priorities of this group through comparison with correspondence education. Using the results of this study, we would be able to achieve the main goal which is higher level of food healthiness.

\section{MATERIALS AND METHODS}

Description of study: This was a cross-sectional study to determine the knowledge level of employees who were working in food preparation and supply centers as the target population with respect to hygiene principles and effectiveness of educational intervention trade school and booklet in Semnan city of Iran.

Sampling method and data collection: Study population comprised of all operators who were working at food supply centers in Semnan at the time of study. Since 1506 food preparation and distribution centers were active at the time of study, the sample size calculated and it was determined as 140 individuals in each group. Six major food supply categories which were studied here and their frequency distribution in Semnan at the time of study were as follows: Groceries $(57 \%)$, restaurants $(10.5 \%)$, fruiterer and greengrocer (7.2\%), butchery (10.8\%), pastry and fruit juice cafes $(5.8 \%)$ and bakery $(8.7 \%)$. These numbers are according to the report of Semnan Health Center in 2010. Due to regional distribution of food preparation and supply centers, cluster sampling method was used for sampling. Three groups each constituted of 140 subjects were included by cluster sampling method from all food supply centers. The educational method for the three groups were as following: the first group received educational programs at a trade school (face to face methods, 135 cases), second group by correspondence method (distant learning, 145 cases) and the third group with no educational intervention as the control group (140 cases).

For data collection, a questionnaire was designed and its validity and reliability were approved. This questionnaire was filled out before and after educational intervention for the three studied groups.

Statistical analysis: The gathered data were entered to the software and statistical analyses including Analysis of Variance (ANOVA) and t-test were done by SPSS software for Windows. A probability level of $p<0.05$ was considered statistically significant.

\section{RESULTS}

A total of 420 operators and workers knowledge of food supply centers before and after educational intervention were assessed. Results of this study have been shown in Table 1-6. Shows that the highest number of participants was working in groceries (48.57\%) regarding the commerce involved. The lowest number was seen in pastry and fruit juice cafes (7.62\%). The most participants have high school education and their record of service was less than five years.

Table 2 presents one-way ANOVA results for the three groups studied. As shown, difference between knowledge score of the three groups is significant after educational intervention $(\mathrm{p}<0.001)$. But no difference was seen before educational intervention $(p=0.134)$. This shows that the interventions performed in this study were effective. A relative growth was seen in the control group which can be due to motivation for learning and more attention to health issues while completing questionnaires or due to the media. 
Am. J. Applied Sci., 9 (10): 1678-1683, 2012

Table 1: Sociodemographic characteristics and frequency of participants in the study

\begin{tabular}{|c|c|c|c|c|c|c|c|c|}
\hline \multirow{2}{*}{$\begin{array}{l}\text { Demographic items } \\
\text { Food services }\end{array}$} & \multicolumn{2}{|c|}{ Participants number } & \multicolumn{2}{|c|}{ Educational booklet } & \multicolumn{2}{|c|}{ Trade school } & \multicolumn{2}{|c|}{ Control } \\
\hline & $\mathrm{N}$ & $(\%)$ & $\mathrm{N}$ & $(\%)$ & $\mathrm{N}$ & $(\%)$ & $\mathrm{N}$ & $(\%)$ \\
\hline$\overline{\text { Grocery }}$ & 204 & 48.57 & 66 & 45.52 & 75 & 55.56 & 63 & 45.00 \\
\hline Restaurant & 54 & 12.86 & 14 & 9.56 & 19 & 14.07 & 21 & 15.00 \\
\hline Vegetable and fruit seller & 41 & 9.76 & 21 & 14.48 & 9 & 6.67 & 11 & 7.86 \\
\hline Chicken and butcher & 51 & 12.14 & 23 & 15.87 & 6 & 4.45 & 22 & 15.71 \\
\hline Pastry and fruit juice cafes & 32 & 7.62 & 7 & 4.83 & 12 & 8.89 & 13 & 9.28 \\
\hline Bakery & 38 & 9.05 & 14 & 9.65 & 14 & 10.36 & 10 & 7.15 \\
\hline \multicolumn{9}{|l|}{ Age (year) } \\
\hline$<21$ & 31 & 7.40 & 8 & 5.51 & 3 & 2.22 & 20 & 14.28 \\
\hline $21-30$ & 112 & 26.70 & 38 & 26.20 & 36 & 26.67 & 38 & 27.15 \\
\hline $31-40$ & 95 & 22.60 & 41 & 28.28 & 28 & 20.74 & 26 & 18.57 \\
\hline $41-50$ & 93 & 22.10 & 30 & 20.69 & 30 & 22.22 & 33 & 23.57 \\
\hline $51-60$ & 52 & 12.40 & 17 & 11.72 & 21 & 15.56 & 14 & 10.00 \\
\hline$>60$ & 37 & 8.80 & 11 & 7.6 & 17 & 12.59 & 9 & 6.43 \\
\hline \multicolumn{9}{|l|}{ Education level } \\
\hline Primary school & 57 & 13.57 & 20 & 13.79 & 19 & 14.07 & 18 & 12.86 \\
\hline Guidance school & 57 & 13.57 & 20 & 13.79 & 21 & 15.56 & 16 & 11.43 \\
\hline High school & 266 & 63.33 & 88 & 60.69 & 79 & 58.52 & 99 & 70.71 \\
\hline College & 40 & 9.53 & 17 & 11.73 & 16 & 11.85 & 7 & 5.00 \\
\hline \multicolumn{9}{|l|}{ Record of service (year) } \\
\hline $0-5$ & 185 & 44.00 & 64 & 44.14 & 46 & 34.08 & 75 & 53.57 \\
\hline $6-10$ & 92 & 21.90 & 29 & 20.00 & 35 & 25.92 & 28 & 20.00 \\
\hline $11-15$ & 47 & 11.20 & 22 & 15.17 & 16 & 11.85 & 9 & 6.43 \\
\hline $16-20$ & 43 & 10.20 & 14 & 9.66 & 16 & 11.85 & 13 & 9.28 \\
\hline$>20$ & 53 & 12.60 & 16 & 11.03 & 22 & 16.30 & 15 & 10.72 \\
\hline Total & 420 & 100.00 & 145 & 100.00 & 135 & 100.00 & 140 & 100.00 \\
\hline
\end{tabular}

Table 2: Comparison of mean and standard deviation $(\mathrm{M} \pm \mathrm{SD})$ of knowledge score before and after educational intervention in three groups

\begin{tabular}{|c|c|c|c|c|c|}
\hline \multirow[b]{2}{*}{ Items } & \multirow[b]{2}{*}{$\begin{array}{l}\text { Trade school } \\
\mathrm{M} \pm \mathrm{SD}\end{array}$} & \multirow[b]{2}{*}{$\begin{array}{l}\text { Educational booklet } \\
\mathrm{M} \pm \mathrm{SD}\end{array}$} & \multirow[b]{2}{*}{$\begin{array}{l}\text { Control } \\
\mathrm{M} \pm \mathrm{SD}\end{array}$} & \multicolumn{2}{|c|}{ ANOVA } \\
\hline & & & & $\mathrm{F}$ & P-value \\
\hline $\begin{array}{l}\text { Knowledge score before } \\
\text { Educational intervention } \\
\text { Knowledge score after }\end{array}$ & $41.98 \pm 15.51$ & $40.89 \pm 12.54$ & $39.81 \pm 13.06$ & 3.407 & 0.134 \\
\hline Educational intervention & $51.04 \pm 11.51$ & $51.88 \pm 14.67$ & $42.62 \pm 13.16$ & 20.680 & $<0.001$ \\
\hline
\end{tabular}

Table 3:Comparison of mean and standard deviation $(\mathrm{M} \pm \mathrm{SD})$ knowledge scores with each other groups after educational intervention

\begin{tabular}{lllll}
\hline Education groups & $\mathrm{M} \pm \mathrm{SD}$ & $\mathrm{T}$ & $\mathrm{df}$ T-test & P-value \\
\hline Trade school & $51.04 \pm 11.51$ & & & \\
Booklet & $51.88 \pm 14.6$ & 0.535 & 278 & 0.593 \\
Trade school & $51.04 \pm 11.51$ & & & \\
Control & $42.62 \pm 13.16$ & -5.59 & 269 & $<0.001$ \\
Booklet & $51.88 \pm 14.67$ & & & \\
Control & $42.62 \pm 13.16$ & 5.55 & 279 & $<0.001$ \\
\hline
\end{tabular}

Table 4:Comparison of mean and standard deviation $(\mathrm{M} \pm \mathrm{SD})$ knowledge score before and following educational intervention in each educated group

\begin{tabular}{|c|c|c|c|}
\hline Items & $\begin{array}{l}\text { Trade school } \\
(\mathrm{M} \pm \mathrm{SD})\end{array}$ & $\begin{array}{l}\text { Booklet } \\
(\mathrm{M} \pm \mathrm{SD})\end{array}$ & $\begin{array}{l}\text { Control } \\
(\mathrm{M} \pm \mathrm{SD})\end{array}$ \\
\hline $\begin{array}{l}\text { Knowledge score } \\
\text { before education }\end{array}$ & $41.0 \pm 15.51$ & $40.89 \pm 12.54$ & $39.81 \pm 13.06$ \\
\hline $\begin{array}{l}\text { Knowledge score } \\
\text { after education }\end{array}$ & $51.04 \pm 11.51$ & $51.88 \pm 14.67$ & $42.62 \pm 13.16$ \\
\hline $\begin{array}{l}\text { Paired } t \text { test and } \\
P \text { value }\end{array}$ & $<0.001$ & $<0.001$ & 0.09 \\
\hline
\end{tabular}

Table 5:Mean knowledge score changes before and after education in the three groups

\begin{tabular}{llcr}
\hline Groups & $\begin{array}{l}\text { Before } \\
\text { education }\end{array}$ & $\begin{array}{l}\text { After } \\
\text { education }\end{array}$ & $\begin{array}{l}\text { Score changes before } \\
\text { and after education }\end{array}$ \\
\hline Trade school & 40.890 & 51.88 & 10.990 \\
Booklet & 41.980 & 51.04 & 9.060 \\
Control & 39.810 & 42.62 & 2.810 \\
ANOVA, & & & 0.016 \\
P- value & 0.134 & $<0.001$ & \\
\hline
\end{tabular}

Table 6: Post-hoc test results for comparing groups after significant ANOVA

\begin{tabular}{lcr}
\hline Comparative groups & Difference of means & Tukey, P-value \\
\hline Booklet and control & 8.18 & 0.013 \\
Trade school and control & 6.25 & 0.036 \\
Booklet and trade school & 1.93 & 0.646 \\
\hline
\end{tabular}

Based on the data of Table 3, a significant difference was seen between the group educated using the booklet and control as well as between the trained group at trade school and control $(\mathrm{p}<0.001)$. No significant difference was seen between the group 
Am. J. Applied Sci., 9 (10): 1678-1683, 2012

educated by booklet and the one which was undergone education at trade school $(\mathrm{p}=0.593)$.

Table 4 depicts the paired $\mathrm{T}$ test results in each group separately before and after education. As shown, a significant difference exists in both educated groups either by booklet or trade school before and after education $(p<0.001)$. The results of paired $T$ test in control group indicates that mean knowledge score did not show significant difference before and after education $(\mathrm{p}=0.09)$.

Table 5 shows mean changes of knowledge score before and after intervention in the three studied groups using one-way ANOVA. The data confirms significance of difference between the three groups after education in comparison to baseline regarding mean knowledge score changes $(p=0.016)$. The difference of Table 5 with Table 4 is that in the former table, the variable is mean difference of score before and after education whereas Table 3 shows mean of scores.

Table 6 presents post-hoc test results following significance of ANOVA (mean score difference). This test showed that there was a significant difference in mean knowledge changes between booklet and control groups $(p=0.013)$ and also between trade school and control groups $(p=0.036)$. But, this difference was not significant between booklet and trade school groups.

\section{DISCUSSION}

Implementation of educating methods can be essential for developing and changing knowledge and practice among employees. The most studies suggested that food hygiene education programs can be a means of improving food safety and hygiene principles in food service centers. Acikel et al. (2008) represented that the most efficient method to stop food related epidemics problem or at the very least to decrease it is by to training those working in the food industry and repeating this training periodically (Acikel et al., 2008).

This study was done due to effectiveness of educational methods for increasing health principles knowledge among employees of food preparation and supply centers. A relative growth was seen in the control group which can be due to motivation for learning and more attention to health issues while completing questionnaires or due to the media. A significant difference was observed between the group educated using the booklet and control as well as between the trained group at trade school and control. Also, there is no significant difference between the group educated by booklet and the one which was undergone education at trade school.

Yeganeh et al. (2006) reported that mean knowledge scores after receiving education has increased in lecture group and in booklet group (Sadrzadeh and Angvrany, 2006). They refer to this word that this increasing knowledge in booklet and lecture group is not significant compared to booklet group alone. We also reached to this outcome and it can be in agreement with our results. Also, Roberts et al. (2008) reported a significant association between education and improvement in knowledge of foodservice employees (Roberts et al., 2008). According to present research, the obtained data confirms significance of difference between the three groups after education in comparison to baseline regarding mean knowledge score changes $(\mathrm{p}=0.016)$. Based on work of Pilling et al. (2008) due to study on the training effects of food handlers on their knowledge in American restaurants, one-way ANOVA showed significant difference between mean differences of knowledge score of trainees compared to control (Pilling et al., 2008). Present study also refer to have a significant difference in mean knowledge changes between booklet and control groups and have a significant difference between trade school and control groups which this difference cannot be significant between booklet and trade school groups. In a study, the mean knowledge scores after education by lecture method in comparison to control increased and this increase was with high score in booklet group compared to control (Sadrzadeh and Angvrany, 2006).

Statistical analyses indicated the significant differences in terms of mean knowledge changes of booklet and lecture groups in comparison to control group in this study. It was found that distance learning by booklet (correspondence method) was more effective than trade school method in increasing the knowledge level of the studied population.

Some researchers commented that lecture method for educating nutrition to students is a more dynamic than using booklets, however due to large number of students in educational systems and the inability for direct training, using educational booklets is more costeffective. This study also demonstrated that knowledge and practice of group trained by lecture and booklet increased significantly compared to control group. This increase was more prominent in lecture but the two methods of education were not different significant (Sadrzadeh and Angvrany, 2006) In a research reported that distant learning had meaningful effects on increasing knowledge scores of high school female students after providing training by booklet (Mohammadpour,2000). A study on the effects of a computer education program (remote) on the Austrian school children about nutrition training showed a significant increase in knowledge of trained students (Kreisel and stumps, 2004). In a research showed the 1681 
significant effects of health education in knowledge of foodservice personnel (Rennie, 1995). Soon and Baines (2012) also reported that the significant differences in participants' level of knowledge were observed in examined people (Soon and Baines, 2012). They found an increase in immediate knowledge gain after training and they suggested that the educational and training program was successful in improving food safety knowledge of participants (Soon and Baines, 2012). Also, Friel and Kelleher (1999) found a significant increase in the knowledge and practice of a group of Irish primary school students after providing a face-toface educational program (Friel and Kelleher, 1999). Mahdi et al. (2006) reported that the mean knowledge score between three groups who were undergone education by lecture, play and role-play were not significant at baseline. But after intervention, mean knowledge scores increased which was the least in lecture group (Mahdi et al., 2006).

Sinclair et al. (2003) found evidence that safety training increases knowledge and they mentioned that the knowledge test scores were apparently higher in the new training units than in the usual training units.

Medeiros et al. (2011) mentioned that the methodological strategies used in training programs designed to enhance food safety in food services (Medeiros et al., 2001). The resources most widely used during the training courses were interactive media, audiovisual materials, videos, lectures and recreational activities. These activities contribute toward the enhancement of employees' skills and knowledge and encourage changes in attitude and behavior.

Dipietro (2006) demonstrated that in class training method is advantageous because it brings many people together at the same place, thus reducing costs, in addition to increasing interaction (Dipietro, 2006). Inservice training allows people to see what is being taught while they work (Dipietro, 2006). Malhotra et al. (2008) mentioned that in addition to lectures and posters, more training techniques are required to solve food safety issues (Malhotra et al., 2008). A study showed that training with the aid of interactive media was better accepted by participants than other methods (Dipietro, 2006). This training method led to more changes in knowledge (Dipietro, 2006). Martins et al (2012) studied to assess food hygiene knowledge of professional food handlers from an institutional catering company which manufactures and distributes meals to the canteens of schools, kindergartens and nursing homes (Martins et al., 2012). They referred that the level of knowledge was influenced by the level of formal education of respondents (Martins et al., 2012). Choudhury et al. (2011) found that the knowledge level of the food employees increased about $42.5 \%$ after training interventions (Choudhury et al., 2011), but we found the rate of knowledge raise was less than 50\% after performing this study and it determines that we did not success at high level in increasing knowledge level of studied population and it needs to revise our training methods.

\section{CONCLUSION}

It was concluded that the important thing according to observed findings is comparison of mean scores in both educated groups after intervention did not show considerable increase. Both methods were not successful in increasing knowledge level of studied population. There is a requirement to develop training methods that they could change knowledge as well as behavior. This necessitates launching appropriate actions for improvement of methods (specially, the method of education) and preparation of appropriate educational content/curriculum and more practical ones. Such training program requires be clearly thinking out, well designing with good baseline data to reach benefit effects.

\section{ACKNOWLEDGMENT}

This study was funded by Semnan University of Medical Sciences; (Research Project No. 198).

\section{REFERENCES}

Acikel, C.H., R. Ogur, H. Yaren, E. Gocgeldi and M. Ucar et al., 2008. The hygiene training of food handlers at a teaching hospital. Food Control, 19: 186-190. DOI: 10.1016/j.foodcont.2007.03.008

Choudhury, M., L.B. Mahanta, J.S. Goswami and M.D. Mazumder, 2011. Will capacity building training inter ventionsgiven to street food vendor sgiveussafer food?: Across-sectional study from India. Food Control, 22: 1233-1239. DOI: 10.1016/j.foodcont.2011.01.023

Costello, C., T. Gaddis, M. Tamplin and W. Morris, 1997. Evaluating the effectiveness of two instructional techniques for teaching food safety principles to quick service employees. J. Food Ser. Sys., 10: 41-50. DOI: $10.1111 / \mathrm{j} .1745-$ 4506.1997.tb00230.x

Dipietro, R.B., 2004. Return on investment in managerial training: Does the method matter? J. Food Ser. Bus. Res., 7: 79-96.

Egan, M.B., M.M. Raats, S.M. Grubb, A. Eves and M.L. Lumbers et al., 2007. A review of food safety and food hygiene training studies in the commercial sector. Food Control, 18: 1180-1190. DOI: 10.1016/j.foodcont.2006.08.001

Friel, S. and C. Kelleher, 1999. Evaluation of the nutrition education at primary school (NEAPS) programme. Public Health Nutr., 2: 549-555. PMID: 10656474 
Gomes, E.N., C.S. Cardoso, A.C. Arajo and J.M.C. da Costa, 2011. Meathandlerstraining in Portugal: Asurvey on knowledge and practice. Food Control, 22: 501-507. DOI: 10.1016/j.foodcont.2010.09.036

Howes, M., S. McEwan, M. Griyths and L. Harris, 1996. Food handler certification by home study: Measuring changes in knowledge and behaviour. Dairy, Food Environ. Sanit., 16: 737-744.

Kassa, H., G.S. Silverman and K. Baroudi, 2010. Effect of a Manager Training and Certification Program on Food Safety and Hygiene in Food Service Operations. Environ. Health Insights, 4: 13-20. DOI: 10.4137/EHI.S4717

Kirby, M.P. and K. Gardiner, 1997. The effectiveness of hygiene training for food handlers. Inter. J. Envir. Health Res., 7: 251-258. DOI: 10.1080/09603129773878

Kreisel, K., 2004. Evaluation of a computer-based nutrition education tool. Public Health Nutr., 7: 271-277. PMID: 15003134

Mahdi, H.M.M., M.H. Taghdisi, H.R.H. Mohaddes and A.H. Zadeh, 2006. The effects of three teaching methods of lecture, training game and role playing on knowledge and practice of middle school girls in regard to puberty nutrition. Strides Dev. Med. Educ., 3: 126-133.

Malhotra, R., P. Lal, K.S. Prakash, M.K. Daga and J. Kishore, 2008. Evaluation of a health education intervention on knowledge and attitudes of food handlers working in a medical college in Delhi India. Asia-Pacific J. Public Health, 20: 277-286. DOI: $10.1177 / 1010539508322242$

Marriott, N.G., 1999. Principles of Food Sanitation. Edn., 4th, Aspen, Gaithersburg, Md., ISBN-10: 0834212323, pp: 364.

Martins, R.B., T. Hogg and J.G. Otero, 2012. Food handlers' knowledge on food hygiene: The case of a catering company in Portugal. Food Control, 23: 184-190. DOI: 10.1016/j.foodcont.2011.07.008

Medeiros, C.O., S.B. Cavalli, E. Salay and R.P.C. Proença, 2011. Assessment of the methodological strategies adopted by food safety training programmes for food service workers: A systematic review. Food Control, 22: 1136-1144. DOI: 10.1016/j.foodcont.2011.02.008

Medeiros, L.C., P. Kendali, V. Hillers, G. Chen and S. Dimascola, 2001. Identification and classification of consumerfood-handling behaviors for food safety education. J. Am. Dietetic Assoc., 101: 1326-1339. DOI: 10.1016/S0002-8223(01)00318-2

Mohammadpour, B., 2000. Effectiveness of Nutrition Educational Note on Knowledge, Attitude and practice of Female Students at First Grade of High School in District 6 of Tehran. MS.c. Thesis, Tehran University of Medical Sciences, Iran.
Montenegro, N.S.N., J.L. Brown and L.F. LaBorde, 2008. Development and assessment of pilot food safety educational materials and training strategies for Hispanic workers in the mushroom industry using the health action model. Food Control, 19: 616-633. DOI: 10.1016/j.foodcont.2007.07.005

Nabali, H., F.L. Bryan, J. Ibrahim and H. Atrash, 1986. Evaluation of training food service managers in Bahrain. J. Environ. Health, 48: 315-318.

Park, S.H., T.K., Kwak and H.J., Chang, 2010. Evaluation of the food safety training for food handlers in restaurant operations. Nutr. Res. Pract., 4: 58-68. PMID: 20198210

Pilling, B.K., L.A. Brannon, C.W. Shanklin, K.R. Roberts, B.B. Barrett, 2008. Food safety training requirements and food handlers' knowledge and behaviors. Food Protection Trends, 28: 192-200.

Powell, D.A., C.A. Jacob and B.J. Chapman, 2011. Review: Enhancing food safety culture to reduce rates of food borne illness. Food Control, 22: 817-822. DOI: 10.1016/j.foodcont.2010.12.009

Rennie, D.M., 1995. Health education models and food hygiene education. J-R-Soc-Health, 115: 75-79. PMID: 7738994

Roberts, K.R, B., Barrett, A.D., Howells, C.W., Shanklin and V.K., Pilling, 2008. Food safety training and foodservice employees' knowledge and behavior. Food Protection Trends., 28: 252-260.

Sadrzadeh,Y. and P. Angvrany, 2006. Comparison of two methods of nutrition education at breakfast on the performance of students in fourth grade girls in Tehran six of Education. J. School Health Health Res. Inst., 4: 72-65.

Seaman, P. and A. Eves, 2010. Perceptions of hygiene training amongst food handlers, managers and training providers: A qualitative study. Food Control, 21: 1037-1041. DOI: 10.1016/j.foodcont.2009.12.024

Seaman, P., 2010. Food hygiene training: Introducing the food hygiene training model. Food Control, 21: 381-387. DOI: 10.1016/j.foodcont.2009.08.005

Sinclair, R.C., R. Smith, M. Colligan, M. Prince and T. Nguyen et al., 2003. Evaluation of a safety training program in three food service companies. J. Safety Res., 34: 547-558. DOI: 10.1016/j.jsr.2003.03.003 PMID: 14733989

Soon, J.M. and R.N. Baines, 2012. Food safety training and evaluation of handwashing intention among fresh produce farm workers. Food Control, 23: 437-448. DOI: 10.1016/j.foodcont.2011.08.012

Yeganeh, S.H., P. Angoorany, S.A. Keshavarz, A. Rahimi and B. Ahmady, 2006. Comparison of two nutrition education techniquies on breakfast-eating practice in primary school girls. Tehran. J. School Public Health Institute Public Health Res., 4: 65-72. 